\title{
EL PUEBLO MAPUCHE, UN PUEBLO CON HISTORIA
}

Fernando Díaz, SVD

En la medida que los distintos pueblos del mundo se van comunicando mejor, se hace también evidente la necesidad de superar los prejuicios raciales y culturales que aún persisten entre ellos. Gran parte de estos prejuicios se reproducen mediante visiones históricas que niegan o desvalorizan a un determinado grupo cultural, reduciéndolo a "prehistoria". Como si la historia fuera privilegio de unos pocos. El pueblo mapuche, aún siendo numéricamente minoritario, es uno de los sectores de la población del pais más significativo en la construcción de la identidad nacional. Negado de diversas formas, su ser diferente, su resistencia a la asimilación, y el hecho de ser parte constitutiva del origen y del presente de la sociedad chilena, lo convierte en un desafio permanente y en la posibilidad real de avanzar hacia una sociedad plural y equitativa.

Nuestro interés al recoger hechos de la historia mapuche y proponerios a la reflexión de las comunidades, el interés es que comprendamos cada vez mejor sus actuales demandas y nos reconozcamos como sociedad pluricultural.

\section{A. Conquista y Resistencia}

Cronológicamente este momento corresponde al periodo que va desde el primer contacto con los españoles en el valle del Mapocho y el alzamiento de 1541, hasta alzamiento general de 1598, que concluye con los primeros parlamentos y acuerdos de paz en 1640. Los protagonistas son un ejèrcito conquistador, liderado por Pedro de Valdivia, y las tribus indigenas cuyo territorio se inicia aproximadamente en el valle central del rio Mapocho y se extendia hacia el sur hasta la isla de Chiloé.

Los primeros cronistas dan nombres y caracteristicas que permiten suponer una diversidad de tribus y costumbres al interior de to que hoy ampliamente se designa como "pueblo mapuche". La característica 
relevante es la de una lengua común. Al menos eso se puede deducir de los topónimos indígenas que van del río Mapocho hasta la Isla de Chiloé.'

El primer contacto de los mapuches con los españoles aconteció, al igual que para la mayoria de los pueblo indigenas, a través de un grupo organizado militarmente para una conquista total. Es decir, la exigencia consistia no sólo en metal y productos de la tierra, sino también la mano de obra esclava y la adhesión a la religión de los conquistadores.

La proclamación del "requerimiento" era la primera demanda de sumisión que los indigenas recibian y equivalia prácticamente a una declaración de guerra Con él se dejaban claras las intenciones de los recién liegados: o se aceptaba o se iba a la guerra total. Alguno pueblos aceptaban procurando evitar la masacre. En el caso mapuche, ya en el primer contacto manifestaron decididamente su tenaz resistencia.

Pedro de Valdivia, que venia del Perú, al llegar a los valles centrales, recibió la sumisión del inca Quilicanta y sus aliados que mantenia sujetos a un cierto grupo de tribus. Michimalonko, el primer jefe mapuche contactado, respondió al requerimiento de Valdivia con suma claridad que no estaba dispuesto a ningun tipo de sumisión .Los españoles eran "nuevos incas" (winka) que venian del norte. Los mapuche ya sabian de sus intenciones, que sometian al servicio esclavo a las familias y que codiciaban el oro por sobre todo. Pedro fundó Santiago en 1541, pero un 11 de septiembre de ese

1 Sobre esle punto no existe unanimidad entrc los autores. El criterio de los topónimos parece indicativo de la lengua común. El nombre mapuche no aparece en las crónicas. El nombre "araucanos" es el más difundido. Se usa la palabra "mapuche" que es como los mismos indigenas se reconocen en la actualidad. Cfr H. ZAPAIER, Aborigenes chilenos a través de cronistas y viajeros. Dedica el capitulo segundo a los "Cultivadores del centro sur. Los pueblos araucanos", pp. 43-100.

La cronica de VIVAR refiere varias veces como Valdivia reali/aba la formalidad del requerimiento' "El general Pedro de Valdivia dijo que los queria docir como su majestad te habia eliviado a poblar aquella tierra y a atraerlos a cllos y a su gente al conocimiento de la verdad y que venia a aqud efecto con aquellos caballeros que consigo traid. y a decirios y darios a entonder como habian de servir a Dios, y habiall de venir al conocimiento de muestra Santa Fe Católica y devoción do su majestad como to habian hecho y hacian todos los indios del Peru. y quc ontendioson que. si salian do par y tes servian y les dabat proviston do ta que tonian. y que, haciendo esto. los tendria por amigos hermanos, y que no les haria daño ninguno on su tierra $m$ en sus indios y mujeres e hijos, ni en sus haciondas. hi los hevaria contra su volumtad: y que si se ponian on arma. y le detendian el cammo y et bastimento. que los mataria y robaria la tierra. "G. VIVAR, Crónica y relación copiosa y verdadera de los reinos de Chilc. Introducción, selección y versión actualizada de Sonia Pinto Vallejos, pp.67-68 Idem, $\rho .92$.

$4 \quad$ "La respuesta que dio y envio fue no queria venir. que antes tonia voluntad y proposito de matat a todos fos soñores que habian venido a le dar la obediencia. y que el estaba en parte tall segura quc no tenia miedo de los cristianos, ni a otros muchos más, y que de alli donde estaba era parte para ofonder y matar a todos cuantos cristianos estabamos y los indios de paz que estaban. "Idem. p. 93. 
mismo año, el jefe Michimalonko atacó e incendió la naciente ciudad. La guerra habia comenzado.

En 1546 el ejército continuó avanzando hacia el sur, fundando pueblos y dejando fuertes en puntos estratégicos. Las distintas tribus del pueblo mapuche comenzaron a organizarse frente a la invasión militar y a la consiguiente fundación de pueblos. En 1598 realizaron una de las primeras acciones bélicas masivas que cambiaron radicalmente el panorama del conflicto. Pelantaro, encabezando las tribus del sur, destruyó todas las ciudades y fuertes fundados al sur del rio Bio-Bio, expulsando a todos los colonos de ese territorio. Esto hizo retroceder todo el proyecto conquistador y dejó claras la fuerza y la organización de las tribus en defensa de su libertad y su territorio.La Corona se vio en la necesidad de crear un ejército profesional, mantenido por la Corona, para defender los sectores conquistados. La guerra con los mapuches dejaba asi de ser un asunto privado en el sentido de empresa financiada por los propios conquistadores.

Junto con la destrucción de las ciudades, se perdieron los lavaderos de oro más importantes y la mano de obra indígena entró en crisis. La incipiente economia sufrió un golpe mortal del cual nunca se recuperó, convirtiendo a la Capitania de Chile en una sangria económica para la Corona.

La región al sur del Bío-Bio se convirtió en refugio para las tribus del norte y en el espacio donde la cultura mapuche continuó reproduciéndose y recreándose a partir de las nuevas condiciones. En efecto, Las primeras décadas de guerra habian comenzado a transformar la vida y las costumbres de pueblo mapuche. Las tribus que económicamente eran cazadores recolectores, con una agricultura básica, se vieron obligadas a transformarse en confederaciones organizadas en permanente estado de guerra. La introducción del ganado, del caballo y del hierro fueron revoluciones profundas. Uno de sus efectos importantes fue la de permitir una organización militar de gran movilidad. Eso, sumado a la organización politica mediante las alianzas tribales, configuraba un sistema descentralizado y flexible que hizo casi imposible derrotar a los mapuches.

Para cronistas como Jerónimo de Vivar, los mapuches eran carentes de religión: "Estos no adoran a ninguna cosa, ni tienen idolos..."." En este primer contacto se implanta la imagen del mapuche como bárbaros, sin Dios, sin ley y sin gobierno, imagen que se mantendrá por varios siglos. A diferencia de los musulmanes o judios, que compartia el monoteismo cristiano, los indigenas son una nueva realidad que precisó repetidas definiciones.

5 Las siete ciudades del sur: Valdivia, Angol, Osorno, Arauco, La Imperial, Santa Cruz y Villarrica, fueron arrasadas

6 G. VIVAR, Op. Cit., p.220 


\section{Puntos relevantes de este periodo}

- Los mapuches identificaron hispano con cristiano, y con sumetimiento. Esto se expreso en el término "winka" que dice relación a "inca" y a los conflictos que los mapuche, tenian ya con la politica de sumisión y tributo del Tahuantinsuyo. De hecho los espatioles habian logrado apoderarse del centro de la estructura politica y económica del Perú y procuraron mantener dicha sumisión en la medida que avanzaron hacia el sur. Las tribus mapuche rechazaron esa sumision y comenzo la guerra de esclavizacion.

- La guerra no era novedad para los mapuches, pero si este tipo de guerra de exterminio, de sometimiento esclavo y muerte. Los mapuches comienzan asi a confrontarse con una sociedad radicalmente diferente a la suya, que los amenaza con el exterminio y a la que se opondrán con todas sus fuerzas.

- Las tribus no eran grupos dispersos sin orden social. sino que mantenian una compleja red de relaciones, que al momento de la guerra se hizo evidente. Organizados militarmente a través de amplias confederaciones, los mapuche establecieron pronto su superioridad militar y se replegaron en el territorio entre el Bio-Bio y Valdivia.

- La incorporación del caballo transformó la economía, la comunicación y la capacidad bélica mapuche. También el caballo fue fundamental en el proceso de expansión hacia las pampas argentinas. lo que significó una ampliación enorme del territorio y un cambio decisivo en la economia.

- Este periodo es tambićn crítico en cuanto al descenso de la población indigena. La transmisión de enfermedades como viruela, tifus sifilis. provoco grandes mortandades. Otro factor importante en la disminución poblacional fue el trabajo esclavo en condiciones infrahumanas. especialmente en la mineria." Todo eso diezmó principalmente las tribus al norte del Bio-Bio. provocando una baja considerable en la población.

La crónica de Vivar refiere la sumision de Oublicanta y los conflicios de este con las tribus mapuches Cir G. VIVAR, Op CAt . p. 9) la poblacion indigena total calculada en un millon. En 15633 sobrevino la peste de? viruela en las que habrian muesto un quinto de la mismir Estibis pestes afectaron

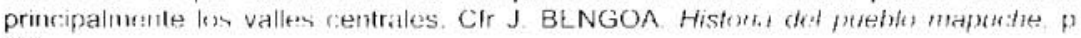
30 


\section{B. Parlamentos y autonomia}

A fines de 1640 y principios de 1641, 90 años después de la destrucción de Santiago y de guerra incesante, se reunieron por primera vez, formal y ampliamente representados, mapuche y españoles, para realizar un acuerdo de paz. Se inauguraba asi una nueva etapa en las relaciones entre mapuche y españoles.

Uno de los motivos principales de este cambio fue la influencia creciente de los jesuitas, que llegados en 1593, trajeron una nueva postura frente al tema indigena. Lo fundamental era el intento de separar la acción misionera del sometimiento militar y la supresión del servicio esclavo. " Para los jesuitas. la guerra a los rebeldes y el maltrato dado a las tribus sometidas, eran un circulo vicioso que solo podia acabar si se suprimia la esclavitud indigena y el servicio personal, principales causas de la situación de guerra y rebeldia indigena.

Una de las figuras principales de este proceso fue el $P$. Luis de Valdivia (1562-1642). A esto se juntaba que después de casi un siglo de guerras y mucha destrucción. la economia colonial estaba en una profunda crisis. El levantamiento general de 1598 habia dejado claro que por la vía de la guerra no se lograria sumisión de parte de los mapuche.

\section{Los parlamentos y las paces de Baides}

En 1639, a fines de un cruento periodo de guerras, que habian hecho retroceder a los mapuche hacia el interior de su territorio, el nuevo gobernador Francisco López de Zúñiga, Marqués de Baides, ofreció la paz a los principales jefes mapuche. Los acuerdos fueron ratificados en tres

10 Los jesuitas Itegan a Chile con una influencia clara de la mision de Juli. donde entre otros estatia el P. Acusta. Fundamental fuc la labor del P. Luis de Vaidivia a su vuelta del Perú en 1612 y hasta 1638, con su propuesta de la guerra defensiva, aunque esta duró formalmento solo hasta 1620 introdujo importantes reformas. Para la Qbra jesurta entre ios mapuche. Cfr R. FUERSTER, Jestitas y mapus:hes. 1593-1767. Sobro ol $P$. Valdivia. Cfr H. ZAPATER, La búsqueda de: la pas en la guerra de Arauco: padre Luis de Valdiviat

11 El P. Valdivia luchó incansablemente por el fin de! servicio personal y su argumentación era clara: " $Y$ es cosa cierta que durante of servicio personaf. no pueden cesar la guerra que es efecto suyo. y con ser esto asi. dicen los gobernadores que hasta que se acaho ha querra, no pueden quitar el servicio personal. excusandose con la misma contmuacion de la guerra de to hacet to que es remedio de ella que es grande inconveniento." L. DE VALDIVIA, [Carta] en: Biblioteca Hispano-Chitena, T.11:60-93. p. 63

12 El P. Luis de Valdivia, natural de Granada, ordenado en 1598, llegó a Santiago en 1593. A pocos años de estar en Chile ya tiene una idea clara de la situación y de la necesidad de acabar con los "agravios" que sufren los indigenas. El pensamiento del $P$. Luis de Valdivia, tiene sus antecedentes en el pensamiento de Las Casas y de teólogos de la época, que sc expresó luego en la bula Subiminis Deus del papa Paulo 1II $\{1537\}$ 
parlamentos, entre Ios anos 1640 y 1641 , de los cuales el más conocido es el celebrado en la localidad de Quitin.

Estos parlamentos son un hito decisivo ya que sentaron el precedente del reconocimiento por parte de la corona hispana de la frontera del rio BioBio y la autonomia del territorio mapuche hasla ol rio Tolten (Cf. Anexo V). Los compromisos asumidos en este parlamento serán referenciales hasta el siglo XIX. Los acuerdos se centraron básicamente en el compromiso mapuche y español de no vulnerar las fronteras. repoblar los valles. Iuchar junto a los españoles contra los rebeldes, dejar a los misioneros predicar en su territorio y devolver los cautivos.'

Estas "Paces de Baides". configuraron una nueva política de relaciones mutuas. que sino acabó con la guerras. por lo menos establecio una forma posible de negociación entre ambas naciones. El "parlamento" pasó a ser la instancia fundamental de negociacion hasta el siglo XIX. alcanzando formas rituales bien defiridas. Como afirma el historiador José Bengoa, "esta no fue una 'graciosa concesion' de su majestad. sino que costó aproximadamente medio millón de muertos al pueblo mapurche".

Entre periodos de guerra y periodos de pac. las relaciones de los mapuche y españoles se fueron transformando profundamente. Guerras y parlamentos. malones y conchavos. misiones y colegios. fuertes y poblados. fueron tejiendo una compleja red de relaciones con la colonia que se proyectó hasta avan<ado el siglo XIX. Una situación paradójica. ya que mediante las armas y la yanaderia. los mapuche mantenian su autonomia, pero mediante el comercio se hacian a su vez dependientes de los bienes y ofertas del mundo colonial.' La autonomia territorial les permitio transformarse lentamente en ganaderos. desenvolver una notable plateria, incorporar nuevas tecnologias. desenvolver su agricultura. desarrollar un amplio comercio fronterizo y expandir sus relaciones suciales y económicas hacia las pampas argentinas. No por eso dejaron de haver guerras y conflictos. Los mapuche mantuvieron su capacidad guerrera, como lo



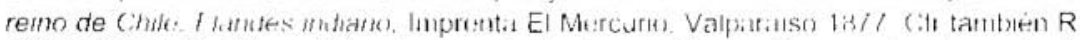

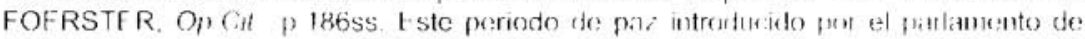

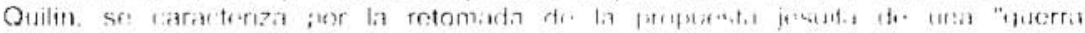
defensiva", propuestat por el P Valdivia a esats alturas exiliesto the t ipratiat 1760. Tapitiue 1//4. Ne:grete 1/93. y us de :81: ason en: patrotixs y 1814 con los

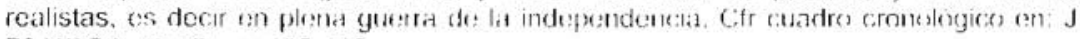
BENGOA. (1), (At , $405,+112$

$15 \quad$ Idem, p. 33

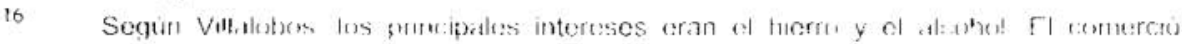



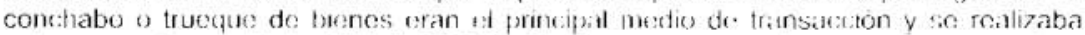

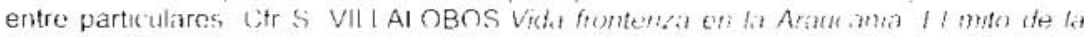
guena de Arauco, p 11/ss 
demostraron los continuos levantamientos. Pero esta belicosidad se fue transformando en una forma de mantener la vigencia de los parlamentos y del equilibrio entre las partes y cada ve $z$ menos en una situacion de guerra total como al inicio.

Las misiones jesuitas se desarrollaron en la Araucania libre, entre 1608 y 1767 . Pasaron del sistema de doctrinas ligadas a encomiendas, a las correrias misioneras ligadas a sus propias ciasas misionales.' Políticamente. su vinculo al papado y su influencia en la corona. les permitió enfrentar los intereses de los gobiemos locales, estableciendo una fuerte hegemonia en cuanto a la actividad misionera entre los mapuche. Su actitud y método evangelizador introdujo un cambio substancial en la misión entre los mapuche, suscitando una fuerte oposición entre autoridades y misioneros de otras órdenes

El primer aspecto fue que consideraron fundamental el aprendizaje del idioma y el conocimiento de aspectos básicos de la cultura indigena, en especial de su universo religioso. Si bien lo consideraban errado, entendian que el demonio los tenia engañados y no que era maldad o incapacidad de los indigenas ${ }^{1 x}$. Asi, el esfuerzo misionero consistia principaimente en convencerlos de cómo el demonio los engañaba y de la superioridad de la verdad cristiana.

Segundo, asumieron la importancia de la gradualidad de la conversión. Procuraron un contacto positivo con las comunidades buscando que aceptasen en primer lugar el rito del bautismo y los sacramentales y simbolos como la cruz. Confiaban más en la fuerza del rito y del simbolo que en el discurso.

En tercer lugar, estaban convencidos que la conversión no tenia posibilidades en medio de un régimen de guerra y de esclavitud. Lucharon para acabar con lo que consideraban los principales impedimentos a la misión: el sometimiento al "servicio personal" y la "guerra ofensiva". Por coherencia ellos mismos debieron terminar con el sistema de encomienda en sus haciendas. Los antecedentes para estas posturas estaban en las

\footnotetext{
1) CFr R. FOERSTER. (I) Cit. p. 369 .

ir El P L Lis do: Valdivia deja ver claramonte su interprotacion dol forror al que tastan

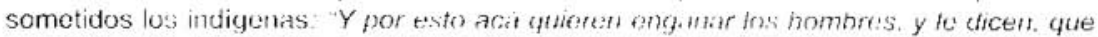
no adoren a Dios. Hi crean en Jesworisto No os emmois tmos mios todos las voces

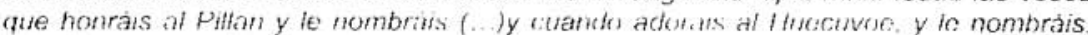

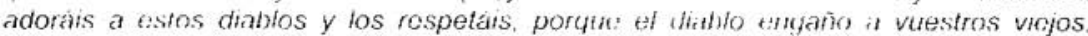
diciendo que se llamaba Pillan. y Huecuvoc, que si Imbierades sabito vosotros, que

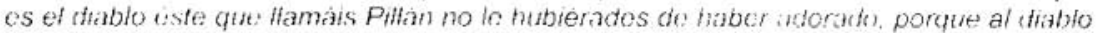

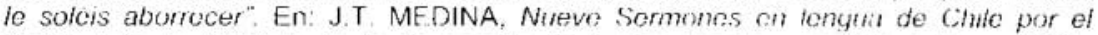
Padre Luis de Vativia do la Compañia de Jesis. impreso en Valladolid en 1621. reimpreso en la Imprenta Elsevirama. Sintiago 1897, p 43.
} 
providencias de Felipe III y en la Bula Sublmmis Deus, del papa Paulo III (1537)

Los jesuitas confiaban que un contacto pacifico y la consecuente convivencia en las misiones, el creciente inlercambio comercial y social de la frontera, llevarian a una nueva situación religjiosa a los mapuche. La doctrina, asociada a la encomienda y al servicio esclavo habia sido un fracaso con los mapuche. Las correrias fueron una alternativa interesante. en cuanto que no habia la exigencia de vincular a los indigenas bautizados a una estructura colonial. ya fuera doctrina o parroquia Batulizarse no era arriesgar la libertad ni las costumbres.

La actividad misionera se desarrolló casi exclusivamente en las márgenes de los territorios libres. Los mapuche rechazaban la penetración de misioneros ligiacta a la llegada de colonos o militares. Cuando concedian permiso para instalar misiones, fue generalmente parte de negociaciones politicas. pa'a asegurar su autonomia frente a las presiones fronterizas o para asegurar las ventajis de los intercambios comerciales.

\section{Observaciones a este periodo}

- Los parlamentos son un triunfo mapucho. Los espanoles se ven forzados a negociar con los mapuche en vista de la imposibilidard de someterlos militarmente. Ritualidad mapuche: y politica hispana constituyen un nuevo escenario de relaciones. Cada uno interpretando los eventos de forma diferente pero en un espaciu y tiempo común. Rito y politicia no so confundieron. pero sirvieron para que dos sociedades. con modos de vida esenciaimente diferentes, elaborasen y llegaran a acuerdos que les permitieran una convivencia pacifica.

- Este periodo de alternancia entre guerras y acuerdos de paz. permite un complejo proceso en que los mapuche van transfurmando su economia y su estructura social.

- Confederacioness mapuche aparecen luchando en diferentes bandos Esto revela una caracteristica social mapuche muy impurtante. No hay jefes absolutos. El poder está desconcentrado. Las alian<as son el mecanismo fundamontal de las confederaciones. El proceso de estratificación social creciente: a partir del atuge de la economia

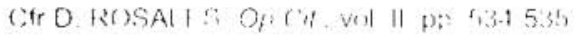

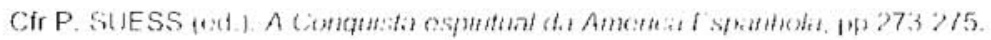

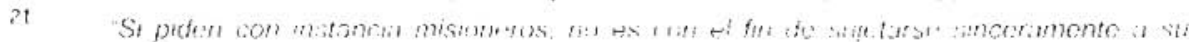

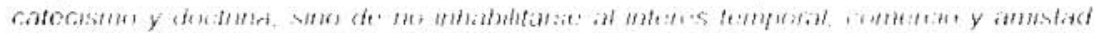

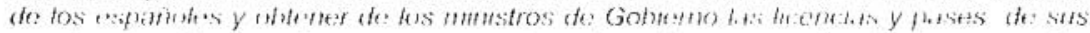

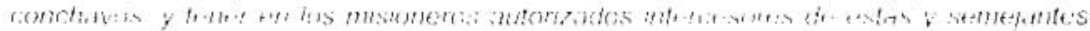

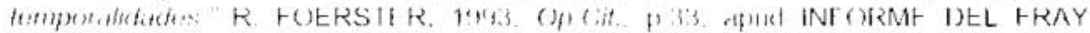
PEDRO ANGEL. DE I SPINE IRA A I AS AUTORIIAADES DFI RIINO EN $1 / 6 /$. Manuscoltos Ment nat yol $194:: 135$ 
ganadera, tensiona la sociedad mapuche y abre brechas por donde los gobiernos coloniales introducirán su juego politico.

- La labor misionera de los jesuitas, como muestra Foerster"2, tuvo dos grandes logros: los parlamentos y la misión separada de la sujeción militar. El parlamento constituyó una forma concreta de reconocimiento de la legitima autonomia mapuche hasta avanzado el siglo XIX y contribuyó en parte a la configuración y autocomprensión actual de la sociedad mapuche.

- La misión, desvinculada de la sumisión, permitio a los jesuitas ofrecer el bautismo como rito abierto a la reinterpretación y por lo tanto, posible de ser incorporado al admapu (tradición), venciendo asi la aversión primera a todo lo que fuera cristiano. El mapuche al apropiarse del bautismo y con él de los nombres hispanos, acepta una dependencia ministerial del sacerdote y se abre a una nueva mediación sociat y religiosa. ${ }^{\text {.+ }}$

- Parlamento y bautismo, perduran en sus efectos hasta el dia de hoy. Los mapuche se constituyeron por medio de los parlamentos en interlocutores validos frente al gobierno colonial. Después de la ocupación, retomaron esta demanda y la mantienen hasta el dia de hoy. El bautismo continúa siendo un rito apreciado por la mayoria de los mapuche. Las iglesias continúan siendo un lugar de interacción directa entre "bautizados" de ambas sociedades.

\section{Guerra, Reducción y Pobreza}

"Llegó la guerra del rei con los chilenos. Mangin se puso del lado del rei. Tenia amistad con los lenguaraces. Ios comisarios i los padres. Todos les decian: "El rei es mejor. Tiene muchas tierras. Los chilenos son pobres; te robarán las tuyas".".

Cfr FOERSII R, Op. Cit, p. 369-373.

Es posible pensar que es en los grandes parlamentos. dondc la conciencia mapuche de ser una nacion crece significativamente. Eri en esos espacios privilegiados que las diversas parcialidades, reunidas para un fin comun, podian mirarse a si mismas como un todo frente a los "otros" no indigenas, estableciendo acuerdos y estrategias comunes.

El bautismo abre la posibilidad de establecer relaciones con el mundo no mapuche. mediante el compadrazgo, permite incorporar al "otro" modiante el nombre. El rito realizado por sacerdotes, es aceptado como un rito positivo dentro del admapu. Sobre las implicaciones de estos pasos en ta comprension de la divinidad es dificil avanzar mucho sin caer en la especulación. 
La sociedad mapuche que llega al sigjl() XIX es una sociedad autónoma. con un territorio propio, gobernado por ellos mismos y con relaciones politicas formales con el gobierno chileno. Su economia era fundamentalmente ganadera y con una fuerte orientación al comercio. La otrora descentralizada sociedad habia comenzado a concentrar autoridad y poder en caciques que a su vez se habian converlido en sus representantes y negociadores con la sociedad colonial.

El poder y la riqueza se habian ido juntando. generando una suerte de estratificacion social de una sociedad que tradicionalmente $\mathrm{SE}$ ? basaba en la familia extensa y en el liderazgo restringido. " Los caciques. a través de las alianzas y de los matrimonios extendian su autoridad formando amplias confederaciones y delimitaban los territorios. constituyendose en una forma primaria de autoridades permanentes. Pero esta estratificación no fue tranquila. muy por el contrario, generaba tensiones internas que se resolvia mediante "malones", alianzas, conflictos armados en bandos diferentes." Las grandes familias. transformadas en linajes dominantes. aparecen durante los siglos XVIII y XIX, envueltos en continuas guerras internas por la hegemonia territorial y politica."

Esta situacion interna de la sociedad mapuche. es importante para comprender que no se trataba de una sociedad estática. sino muy por el contrario. Toda su cultura tradicional se estaba sobrepujando a sí misma para responder a los nuevos desafios que las relaciones con la sociedad colonial le habia generado. Tampoco se trataba de una sociedad caótica o en estado permanente de convulsión. Siempre demostró su capacidad de hacerse representar, de respetar sus acuerdos y de defenderse cuando sentia amenazados sus intereses o su integridad.

Las divisiones internas eran aprovechadas por los espanoles para introducirse mediante alianzas con determinados grupos y controlar los sectores rebeldes. Asi mismo. Ios mapuches usaban sus influencias y estas

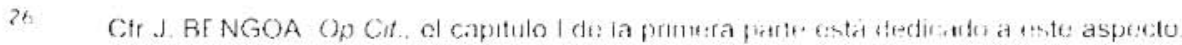
pp. 43 ss;

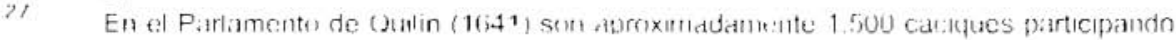

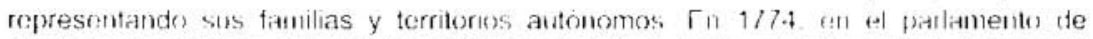

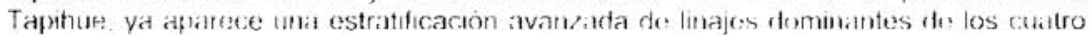

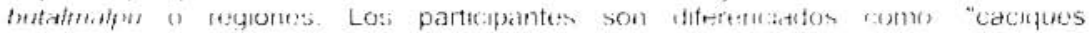
gohernibures". "caciques". "saptamejos" y "mocalmues" de los ruales 276 son caciques 1710 son caphtanejos y motalones los cuales felcueron a 4 representiutes


I apihue. 1/74. Nutram 32 (1993), pp) 16 y 55

Los malones dfal periok ganatero st: caraclerizan por ser una forma de redistritumion

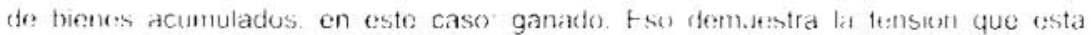
estratifiacion producia en la sociedad mapuche. Clr J. BFNGOA. Op.CA. pp 60 y

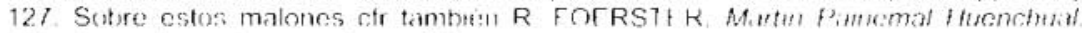

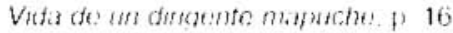

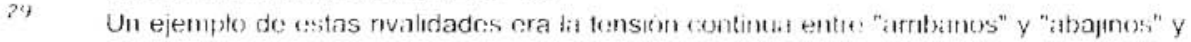
que cra tuente de: contmuos comfluctos Cif J. BF-NGOA. Op (it p 1.30 
alianzas con los españoles para ajustar sus cuentas o establecer sus hegemonias territoriales frente a otros grupos mapuche.

El proceso de independencia de la corona española fue en un comienzo acompañado desde lejos por las parcialidades mapuches; hasta que el escenario bélico se trasladó a su fronteras. En el último parlamento, en Negrete el año de 1803, la frontera habia sido ratificada con el gobierno español. En 1811 se realizó un parlamento en Concepción en el que el nuevo gobierno comunicó a algunos caciques los cambios acontecidos. iv Los realistas, replegados hacia el sur, invocaron frente a los mapuche los tratados con el rey, y en 2 parlamentos generales, 1813 y 1814 , les aseguraron el respeto de sus fronteras y su autonomia. Las confederaciones se dividieron según sus conflictos internos tradicionales. La mayoria de las alianzas mapuche apoyó a los realistas. Una pequeña parte combatió junto al ejercito chileno."

La "guerra a muerte", como la han llamado los historiadores, se desarrolló entre 1819 y 1925 , destruyendo el sistema fronterizo hasta alli vigente. Se trató de una guerra en que se mezclaron las venganzas y conflictos históricos entre los propios sectores mapuche y con los asentamientos criollos de la frontera. "Recién en 1825, con el parlamento de Los Angeles, terminó la guerra directa con el ejército republicano. Sólo hacia 1840 se fue tranquilizando la frontera. Pero la recuperación de la paz fronteriza y la estabilización de la república trajo nuevos problemas.

Otro elemento significativo era el hecho de que tanto en Argentina como en Chile, los mapuche habian participado activamente en las guerras de independencia y luego en los conflictos internos de las nuevas repúblicas, buscando principalmente asegurar la independencia de sus territorios. Con ello el poder militar de los indigenas habia quedado de manifiesto. Una vez terminados los conflictos internos en ambos paises, esto comenzó a ser vistos como una amenaza. Se comenzaba asi a preparar el clima de la guerra y ocupación de la Araucania.

30 A dicho parlamentos asistieron solo 13 caciques y unos 400 mocetones. Cfr J. BENGOA, Op.Cit. p. 141

31 Los abajinos (Colipi y Coñoepan) pactaron con los chilenos; costinos, pehucnches, arribanos y boroanos. con los realistas. Idem, p. 143-144.

32 Los mapuches terminaron enfrentándose entre ellos, como anota BENGOA, sobre lo sucedido en la batalla de Gualeguayco, en Malleco, donde junto al capitán Buines combatieron los caciques Coñoepan, Lempi. Peñoleo (Pinolevi), y por el lado contrario, Mariluan con 800 hombres. En esta guerra de guerrillas, abundaron los actos de crueldad y de depredación, tanto asi, que este episodio, según BENGOA, determinará profundamente la imagen negativa de los mapuche que imperará en la nueva república de Chile. 


\section{La guerra llamada de pacificación}

A mediados del siglo XIX. la expansión sobre las tierras mapuche al sur del Bio-Bio eran un objetivo de los sectores capitalistas de la nueva república. La prensa, a partir de la participación de grupos mapuche en sucesivos conflictos, en 1851 y especialmente en 1859, con asaltos y destrucción de varias ciudades al sur del Bio-Bío, fue modelando una imagen de barbarie. El pais moderno que los gobiernos de la nueva república pretendian formar, comenzaba a ver con malos ojos la permanencia libre de los mapuche al sur de la frontera. ${ }^{3}$

Las colonizaciones extranjeras estaban en auge de Valdivia al sur y el territorio mapuche continuaba siendo un enclave autónomo dentro del nuevo Estado-nación. La via insinuada era la conquista militar y la apertura a los colonos extranjeros. ${ }^{-4}$

En 1866 el parlamento aprueba una ley en que el estado se presupone dueño de las tierras mapuche sin titulo y define la distribución de tierras a colonos y la adquisición del resto mediante remate. Es algo curioso, pues, era evidente que ningún mapuche tenia ni precisaba tener titulo del Estado chileno.

En 1867, ante un nuevo alzamiento mapuche por motivo de los colonos que se adentraban en su territorio, se inició la guerra que duró hasta 1881. El gobierno chileno, que venia saliendo de una guerra contra Perú y Bolivia, aprovechó la victoria y trasladó a la frontera mapuche el mismo contingente militar que venia triunfante de la campaña del norte. Fueron 15 años de guerra llamada irónicamente de "pacificación". La Araucania quedó totalmente bajo control militar. Para los mapuche significó no sólo la perdida de la autonomia politica y territorial, sino por sobre todo, el inicio de su miseria, la explotación y marginación. El ejército entró con la decisión de acabar de una vez por todas con la resistencia indigena. Miles de muertos, heridos y presos. El resto quedó amenazado y en la miseria más absoluta.

33 El periódico El Mercurio de Valparaiso, desarrollo una campana, a partir de la insurrección de 1859. "H araucano de hoy dia es tan timitado, astuto feror y cobarde al mismo tiompo, ingrato y vengativo, cono su progentitot del tiempo do Ercilla; vive. come y bebe licor en exceso como antes (..) En cfecto siompre homos mirado ta conquista de Aratko como ia solucion det gran probloma de la colonizacion y dof progreso de Chite, y recortamos haber dicho con tal motivo que ni brazos ni poblacion es lo que ef pais necesita para su ongrandecimionto industrial y politico, simo terrtorio": Editorial de El Mercurio, 24 de mayo de 1859. Las revueltas politicas de las provincias del sur en 1851 y 1859 contra el gobierno central. buscaron alianza con los mapuches y cuando dorrotados, se refugiaban con caciques amigos. Esto influyó seriamentc en la decision del gobierno rentral de ocupar el territorio mapuche. como modelo para superar las dificultades de la colonizacion espontanea que acontecia en lus sectores de indigenas autonomos. Antonio Varas fue el difusor en Chile del modelo nonteamericano de colonizacion. F. Sarmiento, influyo grandemente, difundiendo la idea tanto en Argentina como en Chile. Cfr J. BFNGOA, Op Cit, p. 173. 
Grandes grupos tuvieron que huir a las montañas, para escapar del cautiverio o la muerte.

La economía mapuche, que se habia transformado en una economia básicamente ganadera, fue destruida abrupta y radicalmente. Miles de cabezas de ganado fueron rematadas o repartidas como botin de guerra. Otras tantas sirvieron de alimento a las tropas. Además de eso, sementeras y casas fueron quemadas, las familias diezmadas. Se trató de una guerra de exterminio, de pillaje y destrucción. Este era el inicio formal de la colonización, organizada por el Estado chileno, del territorio autónomo mapuche ${ }^{i,}$.

Las tierras fueron declaradas fiscales, lo que habria paso a las subastas públicas y a la especulación de la cual nacerán los latifundios. A los mapuche se les comenzó a medir las tierras que "ocupaban" para darles titulos de merced. Se inicia asi el proceso de "radicación" y "reducción".

Paralelamente, en el lado Argentino, las tierras indigenas al sur de Buenos Aires, en gran parte habitadas por mapuche, estaban siendo ocupadas militarmente con una sangrienta campaña. ${ }^{\text {in }}$ Los mapuche quedaron acorralados, separados entre si y empobrecidos de la noche a la mañana. La violencia militar fue de tales proporciones, que ya al comienzo, en 1869, varios periódicos de la época reaccionaron denunciando y condenando los actos del ejército de ocupación.

Al final de la guerra, el desastre era total. Relatos oficiales dan cuenta de miles de mapuche que deambulaban por los fuertes suplicando por

La invasión del territorio mapuche de la Araucania se realizó en forma planificada y no como una reacción frente a los conflictos de frontera. No se trató de una pacificación sino de una colonización planificada con detalle. Cornelio Saavedra, Coronel del ejército y más tarde ministro de guerra y marina, fue el artifice del plan de la ocupación militar y de reducción de los indigenas. BENGOA muestra la clara influencia norteamericana en el modo de plantear y realizarla. Cfr J. BENGOA, Op.Cit, pp. 171174.

Conocida como "Campańa del Desierto" el proceso argentino de expansión se inicia en 1852. En 1879. con la expedición de Roca la ocupación, el desplazamiento y el exterminio alcanzará hasta los últimos rincones. Muchos huyeron a Chile. Cfr CURRUHUINCA-ROUX. Las matanzas del Neuquen. Crónicas mapuche. Además: $R$. MANDRINI, S. ORTELLI, Volver al pais de los araucanos. La semejanza y simultaneidad entre lo que acontece en Chile y Argentina con los mapuche es evidentc. También allà la expansión sobre las tierras indigenas es realizada por el estado, mediante el ejercito, con matanzas y reducción de las tierras indigenas y el ingreso de colonos extranjeros. Ambos paises enfrentaban protilemas similares y habia amplios contactos que llevaron a desarrollar politicas semejantes. Asi también entre los mapuche de ambos lados habia estrechas relaciones comerciales y militares. Cfr J. BENGOA, Op.Cit., p. 198.

37 Por ejemplo: "Estos son los hechos: el general Pinto ha sembrado terrenos fiscales $i$ ha ordenado el arreo de los animales indigenas i el incendio de las rucas i sementeras araucanas; $i$ en vez de guerra de soldados hemos tenido asi en la frontera guerra de pastores $i$ de pillajo desmoralizador." en: El Ferrocarrit, Santiago, 17 de febrero de 1869, p. 2 col. 2. Citado en: J. BENGOA, Op.cit., p. 222. 
alimentos: "En los meses de noviembre y diciembre del año próximo pasado se repartió viveres a 12.606 indios ....".

\section{Radicación y reducción}

En la división de las tierras fue donde se produjo quizás lo que más afectó y transformó la estructura social mapuche. La asignación de tierras a las familias no respetó la organización social que había alcanzado la sociedad indigena. Se crearon "reducciones" bajo el nombre de un cacique, dentro de la cual eran agrupadas varias familias, pertenecieran o no al linaje.

Se creó asi una nueva estructura, que puiverizó la sociedad mapuche en miles de reducciones, diezmadas e incomunicadas entre si. ${ }^{3 "}$ El objetivo claro era quebrar las grandes alianzas y con ello toda posibilidad de recuperar la autonomia. Estas nuevas "comunidades" reduccionales se convirtieron en núcleos de resistencia frente a la sociedad que la envolvia cada vez más. En ellas se procuró resistir y a la vez articular, dentro de lo posible, nuevas relaciones con la sociedad nacional.

Uno de los problemas más dificiles fue el inicio de interminables peleas entre familias. El reparto injusto de las tierras al interior de las reducciones lanzó a las familias unas contra otras. Comenzaron a haber ricos y pobres dentro de las "comunidades". Esto afectó las relaciones y debilitó la solidaridad interna de los clanes. Muchos de esos conflictos perduran hasta el dia de hoy."

En el caos y la arbitrariedad con que se habia llevado la radicación de las familias indígenas, la corrida de cercos, la expulsión violenta, los incendios intencionales y hasta el asesinato, fueron los métodos usados por los colonos para extender sus propiedades sobre tierras indigenas. Los mapuche no tuvieron otro modo de defenderse que recurrir a abogados y jueces de los pueblos vecinos, con escasas o nulas posibilidades de que se fallara a su favor.

Los protectores de indios, los misioneros y los primeros indigenistas, solicitaron al gobierno, de todos los modos posibles, que pusiera atajo a los abusos. Pero elevaron sus voces sin resultado. Sólo entre 1910 y 1930 fueron presentados más de 1.700 litigios entre indigenas y particulares por 357.
Idem, p. 337. BENGOA cita los relatos oficiales de las Memorias de Guerra do 1884

Al terminar la radicación en 1919, se habian entregado 3.078 titulos de merced con una extension de 475.000 hectáreas que favorecieron a unas 78.000 personas. dejando segün cálculos de BENGOA una 40.000 personas sin radicacion. Idem, $p$

La constitución de la propiedad mapuche sc complicó enormemente a partir del momento en que los conflictos entre mapuches se comenzaron a resolver en los juzgados, situacion que supieron explotar un sinnúmero de "abogados" que se enriquecieron a costa de los litigantes. 
causa de tierras mapuche usurpadas. ${ }^{+1}$ La usurpación de tierras llegó a ser uno de los elementos centrales en la formación de la conciencia mapuche del siglo $\mathrm{XX}$ :

"Para la conciencia étnica mapuche se produce un sentimiento de marginalidad, de explotación por parte del conjunto de la sociedad chilena. por tanto de segregación, y también de resentimiento y odio. El tema de las usurpaciones de tierras tiene un trasfondo objetivo indudable: hay tierras usurpadas; sin embargo, el impacto. sobre la conciencia y la subjetividad mapuche es más importante, ya que es la demostración de que la 'guerra de Arauco no ha terminado', de que se sigue acosando al territorio indigena, de que se vive en una sociedad cercada."

Los mapuches ingresan al siglo $X X$, conscientes de haber sido robados, atropellados, empobrecidos y marginados por la sociedad chilena. Es a partir de esa conciencia que se gestaron las nuevas formas de resistencia y de lucha que caracterizarán al mapuche contemporáneo.

\section{LA SOCIEDAD MAPUCHE POS-REDUCCIONAL}

Este punto se refiere principalmente al mapuche de este siglo, confrontado lleno con la sociedad nacional, bajo condiciones de sometimiento y expoliación, obligado a emigrar a los centros urbanos, derrotado militarmente, pero que va retomando el control de su situación y desarrollando nuevas estrategias para reconstruir su proyecto histórico. ${ }^{\text {ti }}$

\section{Organización y participación política}

Si bien es cierto que una gran parte de la población mapuche vivia una seria crisis bajo las nuevas condiciones de empobrecimiento creciente y en la marginación frente a la sociedad nacional, por otra parte comenzaban a surgir formas nuevas de lucha, ya no para expulsar a los invasores, como otrora, sino para conquistar un lugar digno en la sociedad que los estaba incorporando compulsivamente.

Los viejos caciques, derrotados militarmente, poco podían hacer en el nuevo contexto político. Pero ya en la derrota se estaba incubando una nueva forma de lucha. En las zonas de frontera, hacia décadas que muchos caciques y hombres ricos mandaban a sus hijos a estudiar a los colegios

J. BENGOA, Op.Cit, p. 374

Idem, p. 377.

Para este periodo usamos ampliamente la obra de R. FOERSTER, S. MONTECINOS, Organizaciones, lideres, y contiendas mapuche (1900-1970). Cfr también el capitulo 11 de la tercera parte de J. BENGOA, Op.Cit., pp. 365-463. 
misionales. Otros tantos habian sido tomados en prenda de paz durante la guerra. De entre esos jóvenes mapuche, muchos de los cuales habian alcanzado una educación superior, surgieron importantes lideres que iniciaron la defensa de los derechos del mapuche frente al estado y la sociedad chilena. Esa generación, descendientes de linajes importantes, asumió un papel significativo en la defensa de su raza. ${ }^{4}$

En 1903 ya hay datos sobre una reunión del Partido Democrático en casa del cacique Lienan, en las cercanias de Temuco ${ }^{15}$. En 1910 ya se fundó la primera asociación mapuche independiente: la Sociedad Caupolicán Defensora de la Araucania. Básicamente defendian el derecho de los mapuche a una integración justa, es decir, acceso a la educación y justicia frente a la usurpación y remates de tierras indigenas todavia no asignadas. "t

En 1913, a causa de un acto criminal contra un mapuche, conocido como la "marcación Painemal" se produjo la primera protesta masiva de mapuche, en la ciudad de Imperial." Se reunieron cerca de tres mil indigenas. Se pronunciaron discursos y se hicieron demandas al Estado chileno. A partir de este hecho, comienzan los mapuche a conquistar un nuevo espacio, ahora politico, en la sociedad chilena.

En 1917. Manuel Aburto Panguilef, funda la Federación Araucana, que representará una nueva tendencia en la forma de lucha y resistencia mapuche. La reivindicación étnica y social será su combinación principal. Aburto Panguilef, de un modo casi mesiánico, promovia las celebraciones de los ritos tradicionales, el uso de la lengua mapuche, la poligamia y el uso del sueño (peuma) como clave de interpretación y de toma de decisiones ante los diversos acontecimientos. Rechazó la división de las comunidades y defendió la identidad mapuche amenazada por las influencias de la Iglesia y del Estado. Llegó en 1931 a proclamar la "República Mapuche", ligándose abiertamente al proceso de la izquierda de esos años. ${ }^{\text {IN }}$ Con todo esto fue acusado de comunista y descalificado, especialmente por representantes de

Curiosamente un buen grupo de los primeros mapuche formados academicamente. eran hijos de caciques. que durante la última guerra. habian sido tomados en prenda de paz por los militares y luego mandados a estudiar bajo el apadrinamiento de los mismos. Cfr J. BENGOA, Op.cit., p. 386.

$45 \quad$ Idem, p. 387

46 Cfr P. MARIMÁN, "Tierra y legislación indigena. Una mirada desde el prograına del movimiento mapuche (1910-1970)", en Liwen 4 (1997) 143-171.

La marcación Painemal. Se trata de la marcación a fuego de don Juan M. Painemal ocurrida en Nueva Imperial, a manos de un colono de nombre Hernàn Michaeli. Esto provocó tal revuelo, que hasta ese momento. desde el fin de la guerra. los mapuche no se habian manifestado tan masiva y claramente en defensa de sus derechos. Paso asi a ser un hito importante en la historia de la resistencia mapuche. Cfr $J$. BENGOA. Op.Cit.p. p. 381 .

48 En el $11^{\circ}$ Congreso Araucano a fines de 1931. en Raguintucania Cfr J. BENGOA Op.Cit., p. 400 . 
la Iglesia. " Con el tiempo su movimiento perdió fuerza pero fue reemplazado por nuevos grupos organizados.

En 1924 fue elegido diputado el primer mapuche, don Francisco Melivilu. Se inaugura asi la presencia formal mapuche en el aparato politico chileno. Pronto lo siguieron otros diputados, de diferentes corrientes politicas, pero todos partidarios de lo que se conoce como indigenismo integracionista." Es decir, que propiciaban una justa integración del pueblo mapuche a la sociedad nacional, mediante la participación equitativa en la educación. la tierra y los beneficios sociales. El Estado era el principal interlocutor de las demandas sociales.

En 1935 la Sociedad Caupolicán, ya debilitada, se reorganizó y pasó a llamarse Corporación Araucana, la que, dirigida por Venancio Coñoepan, marcará presencia en el movimiento indigena hasta la década de los sesenta. En 1938-39 se funda el Frente Único Araucano. En 1953 se funda la Asociación Nacional Indigenas de Chile en Temuco. El mismo año 1953, se crea la Dirección de Asuntos Indigenas, dependiente del gobierno estatal. Con ella se inaugura el indigenismo estatal.

De este modo, los primeros dirigentes indigenas, lograron introducirse formalmente en el aparato de Estado. En 1959 se celebra el Primer Foro Indigenista del Movimiento de Unificación Araucana en Santiago. En 1969 se funda la Confederación Nacional de Asociaciones Mapuche y celebran el primer congreso en Temuco.

Es dificil saber hasta que punto las ideas de los politicos mapuche y de sus organizaciones, representaron realmente a las bases mapuche, mayoritariamente rurales. Pero es claro que, estos dirigentes politicos y las asociaciones, jugaron un papel decisivo en la reelaboración de la identidad mapuche posreduccional y ayudaron directamente a la representación de un proyecto histórico mapuche frente a la presión integradora de la sociedad nacional. Muchos dirigentes aparecieron vinculados a partidos políticos de izquierda y otros tantos a los de derecha. Pero eran evidentes sus

En 1927. el obispo de la Araucania escribe una carta pastoral a los indigenas condenando las ideas de ABURTO PANGUILEF: "Cumpliendo nuestro sagrado deber de pastor, levantamos publicamente la voz contra unos hombres sin conciencia que tratan de sembrar entre nuestros araucanos. la irreligiosidad. la vuelta al paganismo. y predican el odio contra cierta clase de personas que ellos designan usurpadores de tierras (...) Manuel Aburto Panguilef, asi se llama este seductor del pueblo araucano (..) ha hecho en los uiltimos años una propaganda abiertamente anticristiana. subversiva y funesta (...). " Carta Pastoral del Prefecto Apostólico Fray Guido de Ramberga a los indigenas de la Prefectura Apostólica de la Araucania. 22 de abril de 1927. Diano Austral de Temuco. Ctr J. BENGOA, Op.Cit, pp. 399-400. por dos periodos. Esteban Romero y José Cayupi Catrilaf en 1953. Cfr J. BENGOA. Op.Cit. pp, 388-389. 
verdaderos objetivos: la defensa de la tierra, de la comunidad y de su cultura.

Las organizaciones mapuche acompañaron los procesos políticos y sociales del pais participando donde quiera que se les concedia un espacio. Organizaciones de mujeres mapuche, de profesores mapuche, de estudiantes, de obreros, fueron surgiendo sistemáticamente. Las demandas históricas de recuperación de tierras, de respeto a las comunidades y de acceso a la educación fueron articuladas de diversos modos por todas las organizaciones. Todas las demandas se dirigen al Estado. el que es visto prácticamente como el único interlocutor válido y que debia responder a las demandas del pueblo mapuche.

\section{Movimiento mapuche por la tierra}

Las décadas del 60 y del 70 fueron de gran agitación en el sector rural a causa de las expectativas que creo la Reforma Agraria impulsada por el gobierno del presidente Frei (1964-1973). Para los mapuche la recuperación de tierras usurpadas continuaba siendo su demanda más clara. Las nuevas condiciones politicas impulsaron un gran movimiento mapuche, que se expresó en tomas de terrenos en toda la región de la Araucanía. Dos grandes congresos nacionales mapuche, en 1969 y 1970, dejaron claras sus principales reivindicaciones y permitieron al gobierno elaborar un nueva legislación con base en las demandas mapuche.

La Ley indigena de 1972, al inicio del gobierno de la coalición de izquierda de Salvador Allende, recogió estas demandas y posibilitó una solución para la recuperación de tierras usurpadas. También detuvo la división y enajenación de tierras indigenas, eliminó los Juzgados de Indios y creó el Instituto de Desarrollo Indigena (IDI). " Los mapuche recuperaron en ese periodo un total de 68.381 hectáreas." Hacia 1972 habia más de 40 organizaciones representando al pueblo mapuche.

El golpe de Estado de 1973 y el régimen dictatorial impuesto por el gobierno militar, salvo contadas excepciones, devolvió todas las tierras a los

La nueva ley tenia como objelivo: "a)La recuperacion. aumento y proteccion de todas las tierras indigenas. b)Substituir of sistema vigente de minifundio por uno mas moderno que elcvara et nivel económico de los indigenas. c)lograr la integracion del indigena a la comunidad nacional para su pleno desarrollo. d) Unificar y centralizar la labor def estado para lograr los fines de la nueva politica indigenista : Cfr Documento de discusión de la Ley $n^{\circ} 17.729$. Ley de indigenas, 26 de setiembre 1972. Instituto de Desarrollo Indigena. $\mathrm{s} / \mathrm{d}$. p. 1. Esta ley tuvo una fuerte oposición en el congreso nacional. y terminó siendo aprobada con cambios importantes, especialmente porque abria el camino a la expropiacion de tierras indigenas usurpadas

52 J. AYLWIN. "Antecedentes nistórico-legislativos para el estudio de comunidades reduccionales mapuche", en: Pentukun 4 (1995) 32-33. 
anteriores dueños, desalojando a los indigenas, reprimiendo y desarticulando sus organizaciones. ${ }^{\text {"3 }}$

En 1979 se decretó una reforma de la Ley Indígena de 1972 con el claro objetivo de liquidar las comunidades mapuche. Se implementó la división de las tierras comunitarias y la entrega de títulos de propiedad privada individuales. Con esto los mapuche, pasaban a ser propietarios individuales y dejaban de ser indigenas ellos y sus tierras. Estratégicamente desprotegidas, las nuevas propiedades podian ser arrendadas hasta por 99 años. Casi todas las tierras comunitarias fueron divididas.

El efecto de esta Ley fue que las comunidades mapuche se organizaron y retomaran con mayor fuerza sus demandas históricas. La Iglesia católica jugó un papel estratégico en la reorganización mapuche frente a la dictadura, apoyando la reorganización de las bases mapuche frente al decreto de 1979. Oportunamente, los obispos de la región se manifestaron en una Carta Pastoral, explícitamente sobre los efectos del Decreto Ley. Esto marcó el resurgimiento de la movilización mapuche, que durante la dictadura habia sido paralizada.

Con la abertura política decretada en 1989, se inició el periodo de redemocratización del pais, lo que dio un nuevo impulsó al debate sobre la cuestión indigena. Un número cada vez mayor de organizaciones indigenas comenzó a coordinarse y a participar en el proceso de redemocratización del pais. Aliados con los otros pueblo indigenas del pais, los mapuche plantearon a los sectores democráticos la necesidad que el Estado reconociera los derechos de los pueblos indigenas, derechos territoriales, politicos y culturales. Este proceso culminó con lo que se llamó el "Acuerdo de Nueva imperial" y el compromiso de generar en conjunto con el futuro gobierno una nueva legislación indigena.

Con la promulgación de la Nueva Ley Indigena en 1993, se inició una nueva etapa en la relación entre la sociedad mapuche y el Estado chileno. La creación de la Corporación Nacional de Desarrollo Indigena (CONADI), generó nuevas esperanzas en torno al papel del Estado en cuanto al problema de la insuficiencia de tierras, a la participación en los beneficios sociales, la educación bilingüe y la superación de la discriminación.

Las actuales amenazas al pueblo mapuche provienen del modelo neoliberal de mercado, que impera en el pais. Las tierras indigenas están

53 Cfr E. GACITÚA, "Hacia un marco interpretativo de las movilizaciones mapuche en ios últimos 17 años", en: Nütram 28 (1992) 22-44.

54 Los obispos de las regiones correspondientes al territorio mapuche tradicional, emitieron una carta pastoral, el 4 de mayo de 1979. En ella se refieren directamente a las consecuencias del Decreto Ley 2.568. en el cual "...no se tuvo en cuenta el derecho del pueblo mapuche a participar en la elaboracion de un cuerpo legal trascendental para su futuro." Evangelización del Pueblo Mapuche. Carta Pastoral de los obispos de Concepción, Los Angeles, Temuco, Araucania, Valdivia, Osorno. Temuco, 4 de mayo de 1979, Temuco. 1979, mimeografiado. 
catalogadas de improductivas para la agricultura tradicional, siendo la mayor parte calificada como aplas para la industria forestal. Esto ha provocado una gran presión sobre la propiedad mapuche. Las grandes forestales han adquirido las tierras que eran reclamadas por comunidades indigenas inviabilizando su recuperacion. La reconversion forestal ha transformado profundamente el ecosistema del territorio mapuche, dejando a las comunidades mapuche en dificiles situaciones tanto economicas como ecológicas.

El desarrollo de megaproyectos en territorio indigena es otro punto conflictivo." Las dificultades para armonizar una economia liberal de mercado con las economias de subsistencia caracteristica de los mapuche rurales se han hecho evidentes. La desprotección de los derechos de indigenas sobre sus recursos naturales. tierra, agua y subsuelo, está haciendo crisis frente a un modelo económico basado en la explotación. La nueva Ley Indigena. se ha mostrado insuficiente para proteger efectivamente a las comunidades indigenas y sus territorios.

\section{Territorio, identidad y autonomia}

Los demandas de territorio. identidad y autonomia. resumen en cierto modo la nueva configuración explicita de la demanda mapuche. frente ya no sólo al Estado. sino también frente a la sociedad nacional.

El nuevo discurso de la identidad comenzo a ser formulado por las organizaciones a fines de los ' 80 (demanda del reconocimiento constitucional como pueblo) y cobró peso especialmente con el proceso de transición a la democracia y las expectativas de una nueva legislación indigena." Esto permitio articular la historica demanda por tierra con las nuevas realidades mapuche, especialmente la de los sectores urbanos. estudiantiles y profesionales. Además provocó una reflexión que ayudó a enfrentar las dificultades de perfilar mejor la demanda indigena al interior y frente a los partidos politicos. Con esto se comenzó a abrir un nuevo espacio en la discusión politica: lo étnico. Pero ahora no solo como una discusión de intelectuales, sino como una demanda concreta hacia el mundo social y politico nacional.

Territorio y autonomia son pasos mucho más contundentes que están replanteando elementos de fondo relativos al Estado-nación y a la anexión del territorio mapuche realizada el siglo pasado. Estado plurinacional o pluriètnico, autonomia territorial y autodeterminación, son puntas de lanza de

55 Una serie de temtraless hidroelectricas en la zona del Alto Bics-Bio. territorio mapuche: del grupo Pewenche: ei desvio de la carretera de Temuco bur subre las tierras de las comunidades mapucho de la zona; la carretera de la costa. que esta suendo construida y cruza un amplo territurio mapuche del grupo Latcquenche la construccion de una

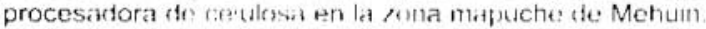

rif CfrE, GACITUA, Op cht . pp. 2\%-44 
una discusión que cada dia se torna más álgida y frente a la cual los sucesivos gobiernos democráticos están teniendo que elaborar respuestas más adecuadas.

El movimiento mapuche ha sabido recoger $y$ articular avances $y$ propuestas de los movimientos indigenas de otros paises, con sus propias demandas. Fundamental ha sido su creciente participación en los foros internacionales. "El cambio sustancial está en que la demanda indigena es cada vez menos la simple "integración" mapuche a la sociedad nacional y cada vez más el reconocimiento y la redefinición de un pacto social que considere al los pueblos indigenas como miembros no solo de hecho, sino también de derecho en la constitución y administración politica y económica del pais.

57 A comienzos de la década de los noventa, la comisión de Derechos Humanos de las Naciones Unidas convocó a la realización de reuniones técnicas y de expertos en torno al tema de derechos indigenas. En 1991 se realizó en Groenlandia una conferencia sobre la autonomia y el gobierno propio de los indigenas. Se estableció en sus conclusiones que los pueblos indigenas tienen derecho a la libre autodeterminación con arreglo a los pactos internacionales de derechos humanos y al derecho público internacional. Parte fundamental de este derecho es el derecho inherente y fundamental a la autonomia y al gobierno propio. Cfr J. AYLWIN, "Pueblos indigenas, territorio y autonomia", en Pentukun 3 (1995) 23-45. Este tema de la autonomia se encuentra ya más elaborada en organizaciones de intelectuales mapuches. Cfr $\mathrm{V}$. NAGUIL, "Desarrollo manuche y derecho de autodeterminación", en: Liwen 4 (1997) 835 . 
